\title{
Reasons for diabetes patients attending Bishop Lavis Community Health Centre being non- adherent to diabetes care
}

\section{Bernice L Booysen \& Arina C Schlemmer}

To cite this article: Bernice L Booysen \& Arina C Schlemmer (2015) Reasons for diabetes patients attending Bishop Lavis Community Health Centre being non-adherent to diabetes care, South African Family Practice, 57:3, 166-171, DOI: 10.1080/20786190.2014.977027

To link to this article: http://dx.doi.org/10.1080/20786190.2014.977027

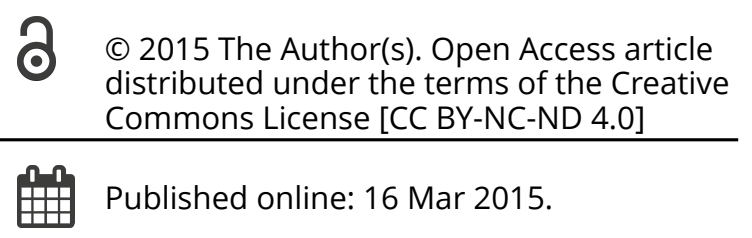

\section{Submit your article to this journal $\pi$}

Џlll Article views: 364

Q View related articles $\square$

View Crossmark data $\asymp$ 


\title{
Reasons for diabetes patients attending Bishop Lavis Community Health Centre being non-adherent to diabetes care
}

\author{
Bernice L Booysen ${ }^{a}$ and Arina C Schlemmera* \\ a University of Stellenbosch, Cape Town, South Africa \\ *Corresponding author, email: arina.schlemmer@gmail.com
}

Background: Non-adherence to diabetes care is a concern at Bishop Lavis Community Health Centre (BLCHC) as it results in many diabetes complications that could have been avoided. The aim was to explore the reasons for people with diabetes in the Bishop Lavis area being non-adherent to diabetes care.

Methods: A qualitative study was undertaken. Focus groups and in-depth interviews were conducted with patients who had uncontrolled blood sugar and non-compliance. The framework method was used to analyse the data.

Results: The main findings in this study were that the following had a negative impact on compliance with diabetes care: (1) poor knowledge of diabetes mellitus; (2) drug treatment barriers such as shift work and not knowing the importance of taking medication regularly; (3) lifestyle adjustment barriers: dietary barriers and lack of exercise; (4) staff and clinic visit problems, for example over-burdened public health-care facilities; and (5) poor support structures including support from family, the community and financially as well as poor infrastructure.

Conclusion: The main findings in this study were consistent with many of the previous studies done on adherence, i.e. patient barriers, disease and drug-regime barriers and doctor-patient relationship barriers. However, in this poverty-stricken area these participants also face other constraints that influence their compliance behaviour. These include (1) over-burdened public health care facilities, (2) insufficient education, (3) poor support structures, (4) infrastructure that is not wheelchair-friendly, (5) unsafe communities, (6) low income and unemployment.

Keywords: diabetes care, diabetes mellitus, non-adherence reasons, primary health care, type 2 diabetes

\section{Background}

Diabetes mellitus (DM) is rapidly emerging as a major public health problem and represents one of the major non-communicable diseases (NCDs) in South Africa. ${ }^{1}$

Unhealthy lifestyle is an important contributor to the rising prevalence of diabetes, with type 2 diabetes accounting for well over $90 \%$ of diabetes in sub-Saharan Africa. ${ }^{2}$

Hearnshaw and Lindenmeyer identified and categorised definitions and measurements of adherence in diabetic patients. They identified five categories, which include coincidence of behaviour with professional advice; relationship as part of the process of care; outcome and process targets; taking the medication as prescribed; and others. ${ }^{3}$

Both non-pharmacological and pharmacological interventions can help to ensure that glycaemic targets are achieved and maintained. Non-pharmacological interventions, such as weight loss through calorie-restricted diets, regular physical exercise and stopping or reducing smoking, play a vital role in all forms of diabetes.

It thus is evident that adherence to diabetes treatment is multifaceted and complicated.

Robyn et al. did research in the USA on adherence with pharmacotherapy for type 2 diabetes and found that $46.2 \%$ of patients ( $95 \% \mathrm{Cl}, 44.7-47.7)$ were non-adherent, based on the Medication Possession Ratio analysis. ${ }^{4}$
Locally, Erasmus et al. assessed glycaemic control in stable type 2 DM black South African patients. At the beginning of this study, the overall mean HbAlc was $9.1 \%$. The target value of $\mathrm{HbAlc}<7$ was achieved in only $20 \%$ of patients. ${ }^{5}$

It is clear that non-adherence is a problem found all around the world. Researchers have identified various reasons for this. To mention two: Puder et al. ${ }^{6}$ found in Switzerland that patient barriers to good management are non-acceptance and absence of symptoms, divergent cultural concepts, chronicity of the disease, specific expectations and beliefs, comorbid conditions and psychiatric disease; El-Kebbi et al.? identified potential barriers (habitual, economic, social, conceptual factors) to dietary adherence in urban African Americans with diabetes. Barriers identified were that most participants missed sugar-containing food items, they felt that they could not afford to buy low-sugar or low-fat foods in addition to other food items necessary for the rest of their family, they found it time-consuming to cook two different meals, and they found the food exchange system difficult to understand and the reading of food labels time-consuming and frustrating.

Non-communicable diseases are closely related to global social and economic development. The rapidly increasing burden of these diseases is affecting poor and disadvantaged populations disproportionately, contributing to widening health gaps between and within countries. ${ }^{8}$

The Bishop Lavis Community Health Centre (BLCHC) is a public care facility on the Western Cape Flats. It mainly serves the community of Bishop Lavis, which is one of the impoverished communities in the Cape Metropole that faces social problems like unemployment, 


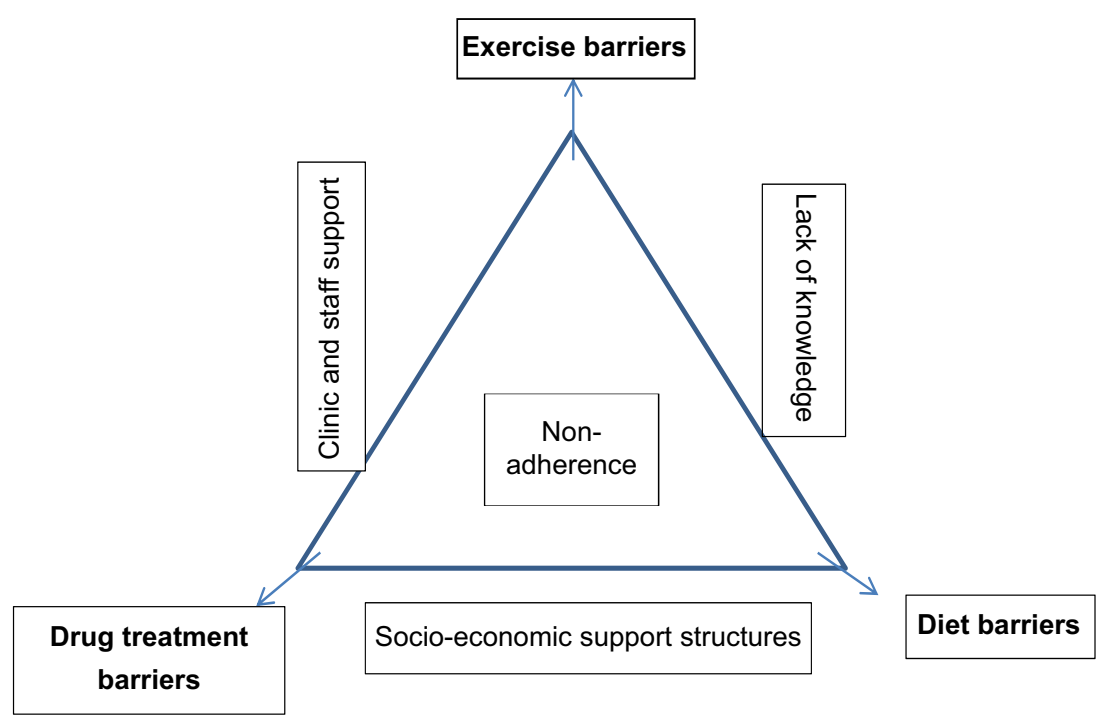

Note: The three corners of the triangle comprise the traditional three main cornerstones on which diabetes management rests (diet, exercise and drug treatment), and the barriers associated with them. The sides of the triangle comprise the support that is needed to enhance adherence to diabetes care, as identified by the study participants, namely clinic and staff support, socio-economic support and knowledge.

Figure 1: The findings of this study

Table 1: Focus group interview 1

\begin{tabular}{llll}
\hline Participant & Age & Gender & Income \\
\hline 1 & 55 & Female & Unemployed \\
2 & 45 & Female & Unemployed \\
3 & 61 & Female & Disability grant \\
4 & 54 & Female & R2 900 per month \\
5 & 57 & Female & Unemployed \\
7 & 75 & Female & Pension grant \\
8 & 37 & Male & Unemployed \\
\hline
\end{tabular}

Table 2: Focus group interview 2

\begin{tabular}{llll}
\hline Participant & Age & Gender & Income \\
\hline 1 & 60 & Female & Unemployed \\
2 & 55 & Female & Unemployed \\
3 & 74 & Pemale & Pension grant \\
4 & 61 & Female & Disability grant \\
5 & 57 & Female & Pension grant \\
6 & 75 & Female & Unemployed \\
\hline 8 & 58 & Female & Unemployed \\
\hline
\end{tabular}

Table 3: Focus group interview 3

\begin{tabular}{lcll}
\hline Participant & Age & Gender & Income \\
\hline 1 & 62 & Male & Pension grant \\
2 & 49 & Male & Unemployed \\
3 & 59 & Male & Unemployed \\
4 & 33 & Male & R4 500 per month \\
5 & 56 & Male & Disability grant \\
6 & 46 & Male & Disability grant \\
\hline
\end{tabular}


crime and gangsterism, unsafe communities, domestic violence, and alcohol and drug abuse. Some $47 \%$ of households in Bishop Lavis have a monthly income of R3200 or less. ${ }^{9}$

One of the services provided at BLCHC is the chronic care of patients with diabetes. One of the goals of BLCHC is to empower patients to take on a bigger role in their own health through group education about diabetes and, if time allows, counselling on a one-to-one basis. The health education team consists of a dietitian, a physiotherapist, a health educator, nursing staff and doctors. Despite these efforts, a large number of poorly controlled diabetes patients as well as regular defaulters prevails. Many of these patients also present with complications of diabetes, such as ischaemic heart disease, strokes, renal impairment, loss of vision, and peripheral vascular disease, resulting in amputations of legs and even death.

In the Western Cape Province, most facilities have managed yearly audits on diabetes care at district level, but up till the end of 2014, patient interviews have not yet been incorporated into these audits.

A study was conducted with the aim to better understand the possible reasons for non-adherence to diabetes care in the impoverished Bishop Lavis area. The objectives were to explore patient understanding of diabetes, how patients perceive the care offered by the diabetes team, the patients' understanding of counselling on lifestyle changes and diabetes care, how patients perceive the feasibility of advice given by health-care workers in their socio-economic circumstances, patients' attitudes towards change, and patients' thoughts on why they are non-adherent.

\section{Methodology}

A qualitative research method was used to explore and gain understanding of the attitudes, beliefs, values and reasoning of diabetes patients by means of in-depth interviews and focus-group interviews to determine why they are non-adherent.

Participants eligible for inclusion in the study were diabetes patients attending the diabetes chronic care group (also sometimes referred to as the "club") who have uncontrolled diabetes (random $\mathrm{Hgt}>12 \mathrm{mmol} / \mathrm{l}$, for the purpose of the study) and

- who admit to not taking their medication as prescribed by the health-care worker;

- or admit to not following a low-fat and sugar-free diet;

- or defaulted on follow-up on one or more occasions in the year prior to the study;

- or who have a waist circumference $>88 \mathrm{~cm}$ for women or $>102 \mathrm{~cm}$ for men.

Three focus groups were held with diabetes patients on different dates in April 2010 [See Tables 1-3].

The first group consisted of both women and men, the second group consisted of only women, and the third group consisted of only men.

Different gender focus groups were conducted because of the dynamics in a focus group. Factors like age, gender and rank have been found to have a significant influence on the outcome of focus groups in terms of the openness of the participants to air their views. In this study, gender might well play a role, as this is still a patriarchal community and women might not have the candour to talk in front of men about exercise, and the men might not want to talk about the diet that is prepared by their wives in front of the women, for example.

Participation was voluntary and all participants gave written informed consent.

The initial exploratory question in all three focus-group interviews (FGIs) was: "What do you know about diabetes?" The author had prepared a discussion guideline from the objectives that gave structure to the discussion. The group members were allowed to interact with each other and the participants were probed to talk about their feelings and thoughts. They were not interrupted while they stayed on the topics the author wished to cover. The FGls were recorded and the recorded material was transcribed.

Focus group interviews may prevent individuals from opening up completely or being spontaneous, with the possibility that one loses valuable information. For this reason, in-depth interviews were also conducted.

A convenience sample of seven patients was interviewed by the author. An interview guide using the above-stated objectives was used, although the participants were allowed to talk freely. The participants were selected from the regular members of the chronic care group, as well as among patients from casualty who were eligible for the study. Patient participation was voluntary and they all gave written informed consent. All the interviews were recorded and the recorded material was transcribed. Four patients were female and three male, the youngest patient's age being 27 . Three were unemployed, two were receiving a pension grant and two were receiving a disability grant.

The five stages of data analysis in the framework method were followed..$^{10}$

Ethical approval was obtained from the Committee for Human Research at Stellenbosch University.

\section{Findings}

See Figure 1 for the findings of this study diagram. The reasons for non-adherence and poorly controlled diabetes that emerged were:

\section{Poor knowledge}

Suboptimal understanding of diabetes mellitus

Most of the participants did not really know exactly what diabetes mellitus is:

Male participant: "I don't know".

Most respondents knew that certain food caused their blood sugar level to rise and that a lack of exercise can contribute to the problem:

Female participant: "You must eat correctly. Diet plays a big role if you have been diagnosed with diabetes. And less stress and lots of exercise".

A few participants said that they thought they had inherited it, as some of their relatives also suffered from DM.

Male participant: "My mom has diabetes, my cousin has it, my dad and uncle as well ...".

Some participants knew that DM can affect certain organs, like the kidneys and eyes, causing kidney failure, blindness, amputations, etc. 
Male participant: "You can go blind”.

Male participant: "You can lose your legs ...".

Female participant: “Your kidneys can be affected”.

Insufficient education and counselling

Most of the participants found the counselling and education offered by students and nursing staff adequate, although they would prefer to have individual counselling sessions.

Some participants felt that the group counselling session did not reach all the patients, as it usually takes place in the mornings and those who have appointments for the chronic care group later in the day miss out. "sometimes participants were informed about one topic but missed out on another".

Some participants felt that they would like to be seen by a doctor more often for counselling.

\section{Drug treatment barriers}

Most of the participants knew that DM is a non-curable disease that needs lifelong treatment. Most knew what their tablets look like, but did not know the names of their medication. Most participants knew how many tablets they should take and when, but did not know the importance of regular intake.

One participant said that his wife put out his medication and he was not sure which tablet was for which illness.

Many participants were aware of side effects caused by the drugs.

One participant said she worked shifts, which interfered with her treatment regime.

Female participant: "Because I worked shifts, I did not take my medication regularly because of the hours I work - when I have to drink the tablets, I am sleeping and by the time I get up, I have missed some tablets, thus I was not very well controlled".

\section{Lifestyle adjustment barriers (dietary barriers and lack of exercise)}

Dietary barriers

Most of the participants had heard of a diabetic diet and had had a consultation with a dietitian in the past, although only a few respondents adhered to a healthy diet and healthy methods in preparing their food.

They found it especially tough when family members ate different meals from theirs. The female participants regarded it as very expensive and time-consuming to cook two meals at a time, as the rest of the family refused to eat "diabetic food".

Many felt that they did not have the means to buy the types of food that were prescribed for them due to economic constraints.

Female participant: "Your diet must be correct but we cannot keep up with the diabetic foods".

Male participant: "No, you will lose your house and your car to afford those foods".

One participant admitted that his wife prepared a healthy diet for him daily, but at weekends he ate anything.
Another participant admitted that at weekends he did not care about his diet, also abusing alcohol over weekends.

An elderly participant said that she ate anything, as she relied on her daughter who did not care about healthy food for her.

A semi-blind disabled participant said he was cared for by his two daughters, who were both intellectually disabled and had no idea what a healthy diet entailed.

Another elderly participant said that, together with her husband's pension grant, they supported unemployed, adult children and grandchildren and did not have the means to buy special food for diabetes. She often went to bed without food.

Female participant: "The pension money is very little, my two children live with us and they do not work. Their children are still at school. Some nights I go to bed without having eaten anything ...".

Many of the male respondents admitted that they relied totally on their spouses for their meals, which were not always healthy or healthily prepared.

\section{Lack of exercise}

Most of the participants knew the importance of exercise, although only some tried to do any sort of physical exercise.

Some participants blamed the unsafe communities for not exercising.

Female participant: "In this area where we live it is too dangerous to walk alone ...".

Some participants felt the need for exercise clubs.

One participant, an amputee, admitted that he had no interest in any form of activity since he was wheelchair bound.

Male participant: "As the climate changes, so has the public changed. They do not want to help you any more if you fall and I cannot see myself lying on the floor or on the ground in the street, and people walk past me. It will break me down morally".

One participant, who lived in a block of flats, found the staircase too tiring and therefore did not leave his home for things he finds "unnecessary", like exercise.

Some participants blamed their comorbidities as reason for not exercising.

Male participant: "My problem is that I started jogging, but then my knees started giving me problems. Then I stressed too much because I thought my legs would have to be amputated so much was the pain I experienced. So I decided not to jog any more".

\section{Problems relating to staff and clinic visits}

Most of the participants knew the importance of regular attendance at the clinic and of collecting their medication on time, although it still happened that they sometimes skipped a visit.

Most of the participants were satisfied with the overall care they received. They pointed out that some staff members went the extra mile, despite staff shortages and long queues. 
A few participants were not happy with the manner in which some of the nursing staff treated them. The nursing staff were perceived as being harsh at times and embarrassed the patients in front of others.

Male participant: "If the patient just dares to say something, they [nursing staff] just wants to attack the patient. And that is not right. But who are the patients? Rather keep your mouth shut ...".

Most of the participants felt that the waiting time was too long.

Male participant: "The procedure - it takes too long. You go from the one to the other. They could have done everything in one time slot. Because when you are weighed your finger can be pricked. Then you go back and see the sister, if she is not happy with you, you have to go to the doctor. But then you have to sit and wait again in the line".

Some of the elderly participants said they were dependent on relatives to accompany them to the clinic and sometimes it happened that those relatives could not take time off from work on that specific appointment date.

Some participants also blamed the weather for keeping them away from the clinic at times. During the winter months they had to leave their houses while it was still dark and they felt that this was risky in an unsafe community. There is no shelter outside the facility to protect them against cold and rain should they show up early at the clinic.

Male participant: "And another thing ... I feel I should just bring to the attention. When you stand in this queue in the morning, and wait for the doors to open, I know the facility doesn't give you that coverage on a rainy day and, or, or windy day ...".

\section{Poor support structures (family, community and financially)}

Most of the participants felt that they had some support from their other family members.

Male participant: "I have a wife that, as she is putting the porridge down, she brings out the bag with the tablets for me to drink. That auntie, she is very strict ...!"

They found it especially tough when family members ate meals different from theirs.

Some elderly patients felt that their carers did not show any interest in their well-being.

A wheelchair-bound participant felt that there was a lack of wheelchair-friendly infrastructure in the community.

Male participant: "And if you look at many places, even government places, it is not wheelchair friendly, and it is not uh uh, friendly for people who walk with crutches".

Some participants felt the need for a diabetes support group in the community.

The perceived detrimental financial impact of diabetes care on the patients, and the problem relating to safety in the community, have been illustrated under previous headings.

\section{Conclusion}

The main findings of this study are consistent with those of many previous studies done on adherence, namely patient barriers, disease and drug regime barriers, and doctor-patient relationship barriers. ${ }^{11}$ However, in this poverty-stricken area these participants also face other constraints that influence their compliance behaviour. These include overburdened public health care facilities, insufficient education and suboptimal knowledge and beliefs, poor support structures, infrastructure that is not wheelchair friendly, unsafe communities and low income, which is a risk for food security.

Primary health care is the foundation of the health-care system. ${ }^{12}$ Currently, primary health care is not sufficiently programmed to deliver preventative or treatment services for NCDs, and South Africa has some way to go to provide integrated primary health care. ${ }^{1}$ The general shortage of health-care professionals has an impact across all aspects of health care. ${ }^{1}$ Health-care professionals at the primary care level should be taught the necessary skills to deal comprehensively with NCDs, as well as the necessary communication skills.

Health care policies should be implemented to support vulnerable populations in chronic disease prevention and treatment, as well as to improve public health care services as a whole. It is therefore encouraging that the government has acknowledged that the current health care system needs reform, especially the re-engineering of primary health care. Huge disparities exist between the public and private health sectors with regard to the accessibility, funding and delivery of health services.

The majority of the population rely on the public sector. It is therefore also encouraging that the Department of Health has embarked on implementing a National Health Insurance plan. The principles for developing National Health Insurance (NHI) are to improve access to quality health care services for the whole population and to provide financial risk protection against health-related expenditures. Universal coverage is no longer a dream for SA and will become increasingly certain if all players work and strive together. ${ }^{13}$

The South African Summit on the Prevention and Control of Non-Communicable Diseases took place in Gauteng from September 12 to 13, 2011. At the summit, the right of all South Africans to enjoy the highest attainable standards of physical and mental health was once again recognised. It was also acknowledged that such high standards cannot be achieved without measures and services at the national, provincial and district levels to prevent and control non-communicable diseases.

Diabetics must pursue a distinct way of living, i.e. change their eating habits, go on a diet, create a healthy lifestyle and stick to it. ${ }^{14}$ Patients might be aware of the necessity of being on a diet, but the majority do not have an understanding of what this entails. ${ }^{14}$ Providing patients with the necessary information is critical in diabetes care. Overburdened public health-care facilities leave little time for the individual education and counselling of the diabetes patient, and of patients with all other chronic diseases for that matter. Mshelia et al. ${ }^{15}$ conducted a study in Nigeria on patients with type 2 diabetes to demonstrate how diabetes management objectives can be achieved in a resource-poor environment by increasing patient-physician contact time and health education. 
People living in poverty, female-headed households, single parents, people living with many siblings, landless people, migrants and immigrants are at risk for and most vulnerable to food insecurity. ${ }^{16}$ Food insecurity is associated with hypoglycaemia and impaired self-management in diabetes patients. ${ }^{17}$ It is with grave concern that the vicious circle is noted whereby NCDs and their risk factors worsen poverty, while poverty contributes to rising rates of non-communicable diseases. ${ }^{18}$

Social support, especially of the aged and disabled, needs attention. According to a review study of strategies and interventions for the improvement of medication non-adherence among older people, social support can affect medication non-adherence in older adults. Older people who received help at home with activities of daily living and their treatment regime from a spouse or female relative were significantly more likely to adhere to medication than those who did not have such in-home support. ${ }^{19}$

According to a study done by Otero-Sabogal et al. ${ }^{20}$ physician-community health worker (CHW) partnering can have a positive impact on patient self-management skills and clinical outcomes. With appropriate training, CHWs can become part of the primary health-care team to improve quality of care. ${ }^{20}$

The community of Bishop Lavis, like that of the rest of the Cape Flats, is plagued by unemployment, gangsterism and drug abuse. This makes it very unsafe for people to walk around for exercise and to leave their houses in the early hours of the morning to be early to queue at the clinic. Drug abuse can also interfere with adherence to treatment. Measures such as visible policing and neighbourhood watch can be explored and implemented to improve safety in these areas.

Most previous studies on this topic were quantitative. As mentioned before, the chronic disease audit undertaken yearly in the Western Cape does not include a patient perspective either.

The limitations of this study include the fact that the researcher is part of the diabetes health-care team at the clinic and knows many of the participants and their background. Her prior knowledge, experience and beliefs could thus have impacted on the results of the study. However, with this in mind, the researcher tried to be as objective and neutral as possible. Due to time constraints, the execution of the interviews also did not take place as planned. Although fewer in-depth interviews were conducted than planned initially, the same themes started to emerge in the interviews.

The different data sources (focus-group interviews, in-depth interviews, tape recordings, transcriptions, researcher's notes taken during interviews) were triangulated to increase the validity of the results.

Further research needs to explore how young diabetes patients in poverty-stricken areas perceive diabetes care in the public sector, and how the patients' own motivation and taking responsibility for their health outcomes are understood and perceived. A follow-up study after the implementation of the $\mathrm{NHI}$, which aims to improve access to and quality of health care in the public sector, should also be undertaken. This study could also be used as an example of how qualitative information can be obtained from diabetes patients for future chronic disease audits.

\section{References}

1. Bradshaw D, Steyn K, Levitt N, et al. Non-communicable diseases - a race against time. MRC [cited 2013 Dec 10]. Available from: www.mrc. ac.za/policybriefs/raceagainst.pdf

2. Hall V, Thomsen RW, Henriksen $O$, et al. Diabetes in Sub-Saharan Africa 1999-2011: epidemiology and public health implication. A systematic review. MS Public Health. 2011;11:564. http://dx.doi. org/10.1186/1471-2458-11-564

3. Hearnshaw $\mathrm{H}$, Lindenmeyer $\mathrm{A}$. What do we mean by adherence to treatment and advice for living with diabetes? A review of the literature on definitions and measurements. Diabet Med. 2006 Jul;23(7):720-8. http://dx.doi.org/10.1111/dme.2006.23.issue-7

4. Hertz RP, Unger AN, Lustik MB. Adherence with pharmacotherapy for type 2 diabetes: a retrospective cohort study of adults with employer-sponsored health insurance. Clin Ther. 2005 Jul;27(7): 1064-73. http://dx.doi.org/10.1016/j.clinthera.2005.07.009

5. Erasmus RT, Blanco B, Okesina $A B$, et al. Assessment of glycemic control in stable type 2 black South African diabetics attending a peri-urban clinic. Postgrad Med J. 1999;75:603-6.

6. Puder JJ, Keller U. Quality of diabetes care: problem of patient or doctor adherence. Swiss Med Wkly. 2003 Oct 11;133(39-40):530-4.

7. El-Kebbi IM, Bacha GA, Ziemer DC, et al. Diabetes in urban African Americans. Use of discussion groups to identify barriers to dietary therapy among low-income individuals with non-insulin-dependent diabetes mellitus. Diabet Educ. 1996 Sept/Oct;22(5):488-92. http:// dx.doi.org/10.1177/014572179602200508

8. WHO: $2008-2013$ action plan for the global strategy for the prevention and control of non-communicable diseases [cited 2013 Dec 10]. Available from: http://whqlibdoc.who.int/publications/2009/9789241597418_eng. pdf

9. City of Cape Town - 2011 Census Suburb Bishop Lavis [cited 2013 Dec 10]. Available from: http://www.capetown.gov.za/en/stats/2011 CensusSuburbs/2011_Census_CT_Suburb_Bishop_Lavis_Profile.pdf

10. Pope C, Ziebland S, Mays N. Qualitative research in health care, analysing qualitative data. BMJ. 2000;320:114-6.

11. German PS. Compliance and chronic disease. Hypertension. $1988 \mathrm{Mar}$ ;11(3Pt2):1156-60.

12. South African declaration on the prevention and control of non-communicable diseases [cited on Google 2013 Dec 12]. Available from: www.doh.gov.za/docs/dcl/2011/draft_declaration_sa.pdf

13. Matsoso MP, Fryatt R. National health insurance: the first 18 months. S Afr Med J. 2013 Mar;103(3):156-8

14. Kheszthelyi S, Blasszauer B. Challenging non-compliance. J Med Ethics. 2003;29:257-9. http://dx.doi.org/10.1136/jme.29.4.257

15. Mshelia DS, Akinosum OM, Abbiyesuku FM. Effect of increased patient-physician contact time and health education in achieving diabetes mellitus management objectives in a resource-poor environment. Singapore Med J. 2007 Jan;48(1):74-9.

16. Kregg-Byers CM, Schlenk EA. Implication of food insecurity on global health policy and nursing practice. J NursScholarsh. 2010 Sept 1;42(3):278-85. http://dx.doi.org/10.1111/j.1547-5069.2010.01351.x

17. Seligman HK, Davis TC, Schillinger D, et al. Food insecurity is associated with hypoglycaemia and poor self-management in low-income sample with diabetes. J Health Care Poor Underserved. 2010 Nov;21(4):1227-33.

18. United Nations. Draft political declaration of the high-level meeting on the prevention and control of non-communicable diseases [cited 2013 Dec 11]. Available from: http://www.doh.gov.za/docs/dcl/2011/ draft_declaration_un.pdf

19. Elizabeth A, Schlenk EA, Dunbar-Jacob J, et al. Medication non-adherence among older adults. J Gerontol Nur. Jul 2004;30(7):33-43.

20. Otero-Sabogal R, Arretz D, Siebold S, et al. Physician-community health worker partnering to support self-management in primary care. Qual Prim Care. 2010;18(6):363-72. 